\title{
Targeting MUCL1 protein inhibits cell proliferation and EMT by deregulating $\beta$-catenin and increases irinotecan sensitivity in colorectal cancer
}

\author{
MAHA ABDULLA ${ }^{1 *}$, THAMER BIN TRAIKI $^{1 *}$, MANSOOR-ALI VAALI-MOHAMMED $^{1}$, \\ MOHAMMAD S. EL-WETIDY ${ }^{2}$, NOURA ALHASSAN ${ }^{1}$, KHAYAL AL-KHAYAL ${ }^{1}$, \\ AHMED ZUBAIDI ${ }^{1}$, OMAR AL-OBEED ${ }^{1}$ and REHAN AHMAD ${ }^{1}$ \\ ${ }^{1}$ Colorectal Research Chair, Department of Surgery; ${ }^{2}$ College of Medicine Research Center, \\ King Saud University College of Medicine, Riyadh 11472, Saudi Arabia
}

Received November 1, 2021; Accepted December 9, 2021

DOI: $10.3892 /$ ijo.2022.5312

\begin{abstract}
With $>1.85$ million cases and 850,000 deaths annually, colorectal cancer (CRC) is the third most common cancer detected globally. CRC is an aggressive malignancy with metastasis and, in spite of advances in improved treatment regimen, distant disease failure rates remain disappointingly high. Mucin-like 1 (MUCL1) is a small glycoprotein highly expressed mainly in breast cancer. The involvement of the MUCL1 protein in CRC progression and the underlying mechanism have been largely unknown. The aim of the present study was to investigate the MUCL1 expression profile and its functional significance in CRC. The Cancer Genome Atlas dataset revealed that MUCL1 expression was higher in colorectal tumor compared with normal tissues. MUCL1 was also revealed to be expressed in human CRC cell lines. The results demonstrated that MUCL1 promoted cell proliferation and colony formation, confirming its oncogenic potential. Silencing MUCL1 with short interfering RNA inhibited the protein expression of $\mathrm{Bcl} 2$ family proteins, such as $\mathrm{Bcl} 2$ and BclxL. Targeting MUCL1 resulted in significant inhibition in cell invasive and migratory behavior of HT-29 and SW620 cells. In addition, the expression of E-cadherin increased whereas the expression of vimentin decreased in MUCL1-silenced cells, confirming inhibition of epithelial-mesenchymal transition (EMT) process. Thus, it was revealed that MUCL1 plays
\end{abstract}

Correspondence to: Dr Rehan Ahmad or Dr Maha Abdulla, Colorectal Research Chair, Department of Surgery, King Saud University College of Medicine, PO Box 7805 (37), Riyadh 11472, Saudi Arabia

E-mail: arehan@ksu.edu.sa

E-mail: mabdulla@ksu.edu.sa

${ }^{*}$ Contributed equally

Key words: mucin-like 1, epithelial-mesenchymal transition, colorectal cancer, migration, invasion, irinotecan a notable role in cell invasion and migration by inhibiting EMT in CRC. Mechanistically, MUCL1 drives $\beta$-catenin activation by Ser-552 phosphorylation, nuclear accumulation and transcriptional activation. Targeting MUCL1 increases the drug sensitivity of CRC cells towards irinotecan. These findings thus demonstrated that MUCL1 acts as a modifier of other pathways that play an important role in CRC progression and MUCL1 was identified as a potential target for CRC therapeutics.

\section{Introduction}

Colorectal cancer (CRC) is the third most common cancer worldwide and the second most common cause of cancer-related death (1). A steady rise of CRC incidence has been observed as a first common malignancy diagnosed among men and the third most common among women in Saudi Arabia (1994-2010) (2,3). During the initial diagnosis, metastasis occurs in $18 \%$ of patients with rectal cancer and in $20-25 \%$ of patients with colon cancer (4). Growth and progression of the tumor during tumor-associated inflammation includes multiple mechanisms such as anti-apoptosis, abnormal proliferation, angiogenesis, cell invasion and metastasis (5). As a key step in enhancing cancer cell invasion and metastasis, epithelial-mesenchymal transition (EMT) plays an important role in CRC progression. During the EMT process, suppression of E-cadherin by the transcription factors Snail and Slug provokes the loss of the epithelial properties and a higher migration and invasion capacity of the cancer cells (6). Thus, the loss of E-cadherin expression and gain of $\mathrm{N}$-cadherin expression in cancer cells, occasionally called 'the cadherin switch', have functional significance in cancer progression (7). EMT is triggered by a variety of signaling pathways, among which Wnt- $\beta$-catenin signaling pathway has been implicated as one of the many primary inducer (8). The human mucin family of proteins includes large proteins with heavy glycosylation designated MUC1 to MUC21 (9). Mucin proteins are divided into secretory (MUC2, MUC5AC, MUC5B and MUC6) and transmembrane forms (MUC1, MUC4, MUC13 and MUC16). The mucins form a physical barrier that provides protection 
for epithelial cells that line the respiratory and gastrointestinal tracts and form the ductal surfaces of organs such as the liver, breast, pancreas and kidney (9). Mucin like 1 (MUCL1), a small glycoprotein also known as small breast epithelium mucin (SBEM) was first discovered 2 decades ago (10). MUCL1 is a breast specific gene which is highly expressed in breast and salivary glands (11). An immunohistochemical study revealed that MUCL1 protein is mostly expressed in breast cancer (10). Previous studies have indicated that MUCL1 expression strongly correlates with TNM staging, higher tumor grade and lymph node metastasis (11-13). Other studies have demonstrated the importance of MUCL1 detection in breast cancer patients as a biomarker for tumor progression and metastasis $(14,15)$. Liu et al (16) detected SBEM expression in breast tumor tissues and blood samples and proposes it as a marker for predicting hematogenous micrometastasis and neoadjuvant chemotherapy response in breast cancer. Recently, Li et al (17) described the role of SBEM in promoting invasion and metastasis by inducing EMT in breast cancer cells. To the best of our knowledge, the association between MUCL1 expression and its function in CRC is still largely unknown. In the present study, the expression of MUCL1 and functional significance in human CRC cell lines was investigated. The expression profile of MUCL1 from TCGA databases was explored in CRC tumor tissues as compared with adjacent normal tissues. The effect of silencing MUCL1 was assessed on cell proliferation, EMT, invasion-migration and drug sensitivity in CRC.

\section{Materials and methods}

Cell culture. Human CRC cell lines HT-29, SW480 and SW620 were purchased from American Type Culture Collection and cultured in RPMI-1640 media consisting of $10 \%$ fetal bovine serum, 100 Unit/ml penicillin and $2 \mathrm{mM}$ L-glutamine (all from Thermo Fisher Scientific, Inc.). SW480 were grown in DMEM media (Thermo Fisher Scientific, Inc.) containing the aforementioned supplements. STR analysis was performed to confirm new batches of cells. All the cell lines were checked for mycoplasma contamination.

MUCL1 expression profile data. GEPIA (http://gepia. cancer-pku.cn/) (18) was used for The Cancer Genome Atlas (TCGA) database and Genotype Tissue Expression (GTEx) projects provided mRNA expression data from colon adenocarcinoma (COAD) and rectal adenocarcinoma (READ). The analysis of the MUCL1 gene (NCBI Entrez Gene ID: 118430) between CRC tumor and normal samples expression data from the TCGA and GTEx projects was investigated in COAD $(\mathrm{T}=275 ; \mathrm{N}=349)$ and READ $(\mathrm{T}=92 ; \mathrm{N}=318)$. UALCAN database (http://ualcan.path.uab.edu/index.html) (19) is based on the TCGA data and is used for gene expression profiling. In the present study, the transcription expression profile of MUCL1 for COAD was evaluated with the default setting in UALCAN. This tool uses Student's t-test and normalized mRNA level as transcript per million (TPM). $\mathrm{P}<0.05$ was considered to indicate a statistically significant difference.

Generation of stable MUCL1 short interfering (si)RNA cells. HT-29 and SW620 cells $\left(2 \times 10^{5}\right)$ were cultured in $2 \mathrm{ml}$ complete media in 6-well plates. After $24 \mathrm{~h}$, when the cells reached 50-60\% confluency, Lipofectamine RNAi/Max reagent (10 $\mu \mathrm{l}$; Thermo Fisher Scientific, Inc.), control siRNA (5 $\mu 1$; 50 pmols); cat. no. SC37007 Santa Cruz Biotechnology, Inc.) and MUCL1 siRNA (5 $\mu$ l; 50 pmols); cat. no. SC95777; Santa Cruz Biotechnology, Inc.) were diluted in Opti-MEM medium (150 $\mu \mathrm{l}$; Thermo Fisher Scientific, Inc.). Diluted siRNAs and Lipofectamine RNAi/Max reagent were mixed together (1:1 ratio) and kept under the cell culture hood for $30 \mathrm{~min}$ at room temperature. Complex of siRNA and Lipofectamine was added drop-wise to cells and incubated at $37^{\circ} \mathrm{C}$ for $6 \mathrm{~h}$. Then $1 \mathrm{ml}$ of complete medium was further added. The following day, fresh medium was replaced and the mixture was incubated for $48 \mathrm{~h}$ at $37^{\circ} \mathrm{C}$. For selection of stably transfected cells, cells were treated with puromycin (MilliporeSigma; $2 \mu \mathrm{g} / \mathrm{ml}$ ) and incubated at $37^{\circ} \mathrm{C}$ further for 3-5 days. Gradually fresh media was replaced every 3-4 days. Stable cells were maintained at $0.5 \mu \mathrm{g} / \mathrm{ml}$ puromycin.

Western blotting. HT-29 control siRNA and HT-29 MUCL1 siRNA clones (ML1 and 2) as well as SW620 control siRNA and SW620 MUCL1 siRNA clones (ML1 and 2) were cultured in RPMI-1640 complete medium with puromycin $(0.5 \mu \mathrm{g} / \mathrm{ml})$. Preparation of total cell lysates was conducted by harvesting cells followed by PBS washing. The cell pellets were added with RIPA lysis buffer (Boston Bioproducts, Inc.) for $15 \mathrm{~min}$ at $4^{\circ} \mathrm{C}$ followed by centrifugation at $17,530 \mathrm{x} \mathrm{g}$ for $15 \mathrm{~min}$ at $4^{\circ} \mathrm{C}(20)$. Supernatant having the soluble proteins was collected and the concentration of proteins was determined on Bio-Rad SmartSpec Plus spectrophotometer using Bradford protein assay reagent (Bio-Rad Laboratories, Inc.). Equal amount of proteins (10-20 $\mu \mathrm{g}$ ) were loaded on electrophoresis gels (4-20\% Mini-Protean TGX precast gels; Bio-Rad Laboratories, Inc.). The gels were transferred to $0.2-\mu \mathrm{m}$ PVDF membrane by turbo transfer system (Bio-Rad Laboratories, Inc.). The membranes with transferred proteins were blocked in Sea Block blocking buffer (cat. no. 37527; Thermo Scientific, Inc.) for $1 \mathrm{~h}$ at room temperature, followed by washing twice with PBS containing $0.1 \%$ Tween-20 (PBST). Subsequently, the membranes were incubated overnight at $4^{\circ} \mathrm{C}$ with the following primary antibodies: MUCL1 (cat. no. NBP1-92366; 1:500; Novus Biologicals, LLC), Bcl2 (cat. no. sc-492; 1:1,000), BclxL (cat. no. sc-56021; 1:1,000), caspase-3 (cat. no. sc-56053; $1: 1,000)$, E-cadherin (cat. no. sc-8426; 1:1,000), vimentin (cat. no. sc-6260; 1:1,000), Lamin B (cat. no. sc-374015; $1: 1,000)$ and $\beta$-actin (cat. no. sc-47778; $1: 2,000$ ) (all from Santa Cruz Biotechnology, Inc.). Phospho- $\beta$-catenin-Ser-552 (cat. no. 9566; 1:1,000) and $\beta$-catenin (cat. no. 8480; 1:1,000) were purchased from Cell Signaling Technology, Inc. The following day after washing, the blots were incubated with HRP-conjugated rabbit secondary (cat. no. sc-2357; 1:3,000) and mouse secondary (1:3,000; cat. no. sc-516102) (both from Santa Cruz Biotechnology, Inc.) antibodies on a shaker for $1 \mathrm{~h}$ at $25^{\circ} \mathrm{C}$. Chemiluminescence signal was detected by incubating the blot membrane with Pierce ECL western blotting substrate (Thermo Fisher Scientific, Inc.) and detected on a C-DiGit blot scanner (LI-COR Biosciences). Densitometry was carried out using C-DiGiT blot scanner software (Image Studio Digits 3.1; LI-COR Biosciences). 
Colony formation assay. Colony formation assay was performed as previously described (20). HT-29 control siRNA and HT-29 MUCL1 siRNA clones (ML1 and 2) as well as SW620 control siRNA and MUCL1 siRNA clones (ML1 and 2) were harvested and centrifuged at $252 \mathrm{x}$ g for $5 \mathrm{~min}$ at $4^{\circ} \mathrm{C}$. The respective cells were added into 6 -well plates at 500 cells/well containing $2.0 \mathrm{ml}$ RPMI-1640 media. The media was replaced with fresh medium every 3-4 days. The plates were incubated at $37^{\circ} \mathrm{C}$ for $10-12$ days in a $5 \% \mathrm{CO}_{2}$ incubator. Groups of $>50$ cells were considered a colony. Using $4 \%$ paraformaldehyde the colonies were fixed for $10 \mathrm{~min}$ at room temperature and stained with $0.1 \%$ crystal violet for $15 \mathrm{~min}$ at room temperature. The quantification of colonies was performed by using a light inverted microscope (Micros Austria) at x10 magnification.

Cell proliferation assay. Cell Counting Kit-8 (CCK-8) assay was performed using CCK-8 reagent (APExBIO Technology LLC). HT-29 control siRNA and HT-29 MUCL1 siRNA (ML1 and 2) as well as SW620 control siRNA and SW620 MUCL1 siRNA (ML1 and 2) transfected cells were seeded into a 96-well plate at 5,000 cells/well. After 24, 48, 72 and $96 \mathrm{~h}$ cells were incubated with CCK-8 reagent $(10 \mu \mathrm{l})$ at $37^{\circ} \mathrm{C}$ for $2 \mathrm{~h}$, and the absorbance was measured at $450 \mathrm{~nm}$ using a microplate reader (BioTek Instruments, Inc.). The mean and standard deviation (SD) values of three independent experiments were collected.

Transwell invasion/migration assay. Migration was analyzed by Transwell chamber assay using cell culture inserts with a polycarbonate filter (24-wells, $8-\mu \mathrm{m}$ pore size with polycarbonate membrane; Thermo Fisher Scientific, Inc.). Invasion assay was performed by using the same cell culture insert coated with growth factor-reduced Matrigel. Coating was done with cold Matrigel followed by overnight incubation at $37^{\circ} \mathrm{C}$. HT-29 control siRNA and HT-29 MUCL1 siRNA (ML1 and 2) as well as SW620 control siRNA and SW620 MUCL1 siRNA (ML1 and 2) $\left(1 \times 10^{5} /\right.$ well) were seeded onto Matrigel-coated inserts in serum free RPMI-1640 media with lower chamber containing complete RPMI-1640 media. The cells were allowed to invade for $48 \mathrm{~h}$ at $37^{\circ} \mathrm{C}$. Remaining cells above the insert membrane were cleared with a cotton swab. The invasive cells were fixed in $25 \%$ methanol for $15 \mathrm{~min}$ at room temperature followed by washing with cold $1 \mathrm{X}$ PBS. The cells were stained with $0.1 \%$ crystal violet for $15 \mathrm{~min}$ at room temperature followed by 2-3 times washing with 1 X PBS and air-dried. The invasive cells were counted on the representative sections using an inverted light microscope (Micros Austria) at x10 magnification. Counting was performed in five random fields in each group; the number of invasive cells for each sample represents the average of triplicate wells over three experiments. Similarly, migration assay was carried out using normal cell culture inserts.

Cell fractionation. Cells were harvested and washed with PBS and pellets were incubated with $500 \mu 1$ fractionation buffer (20 mM HEPES, $10 \mathrm{mM} \mathrm{KCl,} 2$ mM MgCl2, $1 \mathrm{mM}$ EDTA, $1 \mathrm{mM}$ EGTA, $1 \mathrm{mM}$ DTT and protease inhibitor) for $15 \mathrm{~min}$ on ice. Cell suspension was passed through 1-ml syringe with 27-gauge needle 10 times and incubated for $20 \mathrm{~min}$ on ice. The mixture was centrifuged $805 \mathrm{x} \mathrm{g}$ for $5 \mathrm{~min}$ at $4^{\circ} \mathrm{C}$. The pellet contained nuclei; supernatant would contain cytoplasm, membrane and mitochondria. This supernatant was further centrifuged at $10,000 \times \mathrm{g}$ for $30 \mathrm{~min}$ at $4^{\circ} \mathrm{C}$ to obtain the cytosolic fraction. Nuclear pellet was incubated with $500 \mu \mathrm{l}$ of fractionation buffer again for $15 \mathrm{~min}$ on ice and passed through a 25-gauge needle 10 times and centrifuged at $805 \mathrm{x} \mathrm{g}$ for $10 \mathrm{~min}$ at $4^{\circ} \mathrm{C}$ resulting in the nuclei-containing pellet. This pellet was incubated with RIPA lysis buffer on ice for $15 \mathrm{~min}$. The suspension was sonicated briefly and centrifuged at $17,530 \mathrm{x} \mathrm{g}$ for $15 \mathrm{~min}$ at $4^{\circ} \mathrm{C}$. The supernatant was nuclear fraction which was stored in $-80^{\circ} \mathrm{C}$ until further use.

Flow cytometric analysis of apoptosis. Apoptosis (early and late) and necrosis were determined as previously described (20). Briefly, HT-29 control siRNA and HT-29 MUCL1 siRNA (ML1 and 2) as well as SW620 control siRNA and SW620 MUCL1 siRNA (ML1 and 2) cells were plated in 6-well plate at a density of $1 \times 10^{5} /$ well and cultured for $24 \mathrm{~h}$ at $37^{\circ} \mathrm{C}$. The cells were treated with different concentrations $(50$ and $100 \mu \mathrm{M})$ of irinotecan (IRI) for $24 \mathrm{~h}$ at $37^{\circ} \mathrm{C}$. The cells were harvested along with media by centrifugation at $252 \times \mathrm{g}$ at $4^{\circ} \mathrm{C}$. After centrifugation, the cells were washed twice with cold PBS. Annexin V/Dead cell apoptosis kit (cat. no. V13242; Thermo Fisher Scientific, Inc.) was used according to the manufacturer's instructions to detect cell death. The cells were resuspended in binding buffer followed by addition of Annexin V-FITC $(5 \mu \mathrm{l})$ and $1 \mu \mathrm{l}$ propidium iodide for $15 \mathrm{~min}$ in dark at room temperature. The acquisition and analysis of data were performed using a flow cytometer (BD FACSCalibur) and CellQuest Pro Ver 6.0 software (both from BD Biosciences).

Statistical analysis. All the experiments were performed in triplicate and the results were expressed as the mean of three independent experiments (mean \pm standard deviation). Statistical analyses were performed using GraphPad Prism 7.0 (GraphPad Software, Inc.). Comparison between the control and multiple groups was performed using one-way analysis of variance (ANOVA) followed by a Tukey's post hoc test. In certain analyses, two-way ANOVA was performed followed by Bonferroni post hoc test. $\mathrm{P}<0.05$ was considered to indicate a statistically significant difference.

\section{Results}

MUCL1 expression profile in CRC. Global mRNA gene expression profiling revealed significantly increased levels of MUCL1 mRNA in CRC tumor tissues compared with adjacent normal tissues (Fig. 1A) (21). The MUCL1 gene expression in GEPIA database was then analyzed. It was identified that MUCL1 expression was upregulated in COAD $(n=275)$ compared with normal tissue $(n=349)$ when analyzed in the TCGA/GTEx COAD dataset (Fig. 1B). Similarly, MUCL1 gene expression was revealed to be higher in READ $(n=92)$ when compared with normal tissue $(n=318)$ (Fig. 1C). Notably, MUCL1 expression was increased during CRC stage IV compared with other stages when analyzed in COAD and READ (Fig. 1D and E).

By exploring the UALCAN database, MUCL1 expression was further analyzed in COAD. The results revealed the significantly elevated levels of MUCL1 mRNA in primary 
A

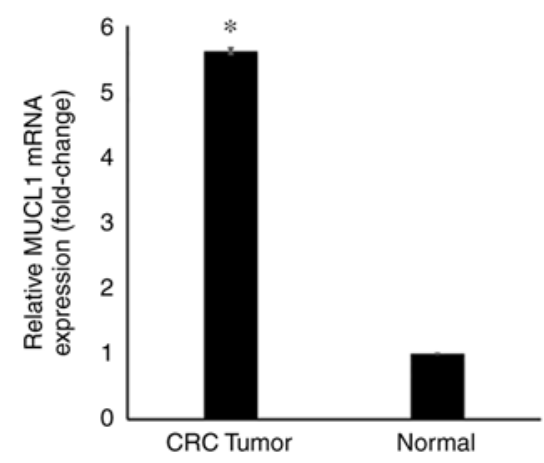

B

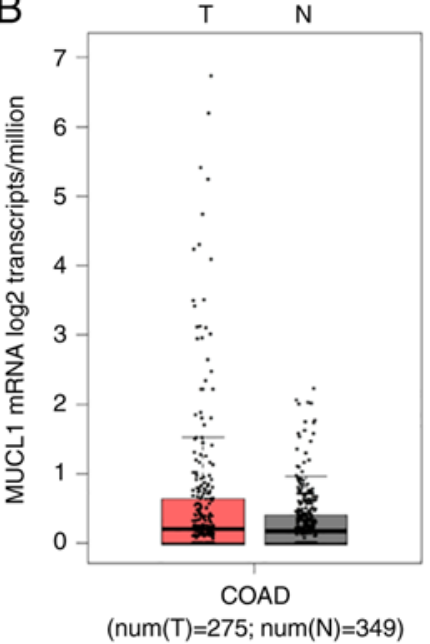

C

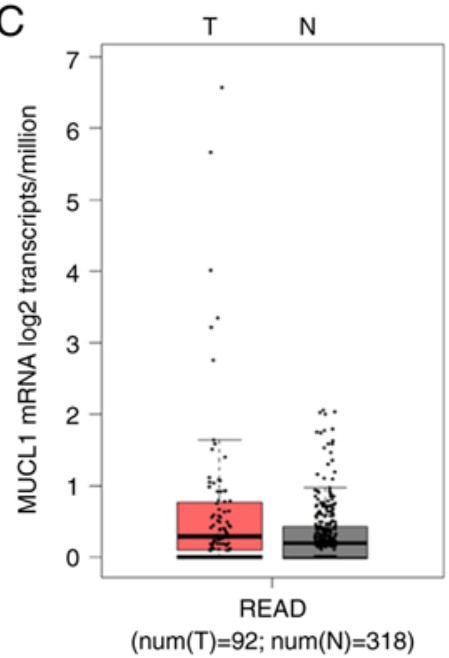

D

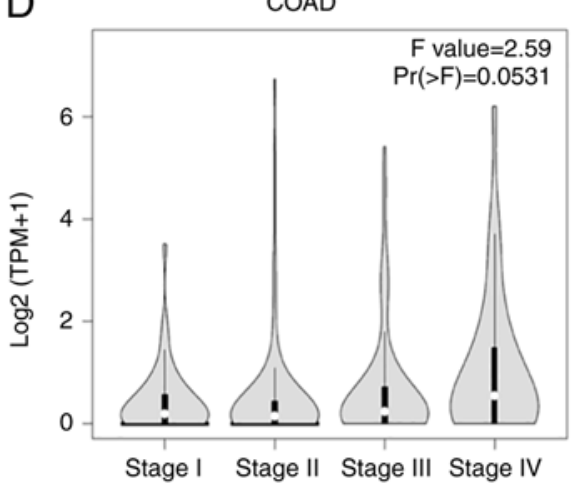

E

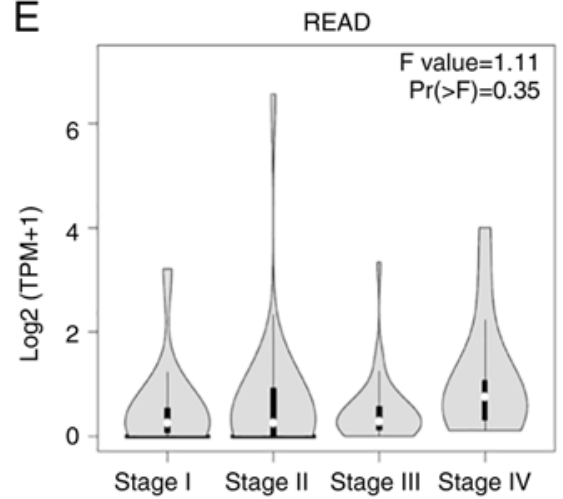

Figure 1. MUCL1 gene expression analysis in CRC. (A) MUCL1 expression in CRC (fold-change) compared with adjacent normal tissue based on microarray data. Data are presented as the mean \pm SD. $(n=13)$. (B) Boxplot comparing the expression of MUCL1 in a cohort of COAD ( $n=275)$ compared with normal colon tissue $(n=349)$ from the TCGA and GTEx datasets. (C) Boxplot comparing the MUCL1 expression in a cohort of READ ( $\mathrm{n}=92$ ) compared with normal rectal tissue ( $n=318)$ from the TCGA and GTEx datasets. (D) Stage plot of MUCL1 expression in colon cancer stages in COAD. (E) Stage plot showing MUCL1 expression in rectal cancer stages in READ. * $\mathrm{P}<0.05$ vs. normal. MUCL1, mucin-like 1; CRC, colorectal cancer; COAD, colon adenocarcinoma; READ, rectal adenocarcinoma; TCGA, The Cancer Genome Atlas; GTEx, Genotype Tissue Expression.

COAD tumor $(n=286)$ compared with normal tissue $(n=41)$. Stage-wise analysis of COAD revealed that MUCL1 expression was significantly higher in stage III as compared with normal tissue (Fig. 2A). Furthermore, MUCL1 expression was significantly higher in adenocarcinoma compared with normal tissue. Expression of MUCL1 was significantly elevated in N1 compared with normal (Fig. 2B). Additionally, MUCL1 expression was significantly higher in women, in patients of African-American decent, in obese patients, in 61-80 years old patients and in individuals bearing the TP53-mutant (Fig. 2C-E). Thus, these findings demonstrated that MUCL1 gene expression was higher in CRC.

MUCL1 protein expression has not been reported in human CRC cell lines. The present study attempted to determine MUCL1 expression by western blotting. MUCL1 was identified to be expressed in HT-29, SW480 and SW620 cells. MUCL1 expression was low to moderate in adenocarcinoma cell lines (HT-29 and SW480) with significantly higher expression observed in the metastatic CRC cell line SW620 compared with HT-29 (Fig. 3A). This finding indicated that MUCL1 was expressed to a varied degree in CRC cell lines. To understand the functional significance of MUCL1 expression in CRC, MUCL1 was silenced in HT-29 and SW620 cells using siRNA; two clones (designated as ML1 and 2) were selected for further experimentation. MUCL1 gene was revealed to be inhibited with siRNA in both cell lines as shown by western blotting (Fig. 3B and C).

Inhibiting MUCL1 decreases Bcl2 family protein and activates caspase-3. Cancer cell survival depends on a set of proteins that regulate cell proliferation and block apoptosis. Bcl2 family proteins consist of pro-apoptotic (Bax and Bak) and anti-apoptotic (Bcl2, BclxL and Mcl1) proteins (22). The balance between pro-apoptotic vs. anti-apoptotic proteins determines the cancer cell fate. MUCL1 silencing was found to significantly inhibit $\mathrm{BclxL}$ and, to certain extent, $\mathrm{Bcl} 2$ in HT-29 cells. Both Bcl 2 and BclxL were significantly inhibited in SW620 cells (Fig. 3D and E). In the apoptotic pathway, cytochrome c release into cytosol forms a complex with Apaf1 and procaspase-9, which is called apoptosome and results in the autoactivation of caspase- 9 and activation of downstream caspase-3 (23). It was investigated if there was any caspase activation by measuring cleaved caspase-3. Indeed, targeting MUCL1 by siRNA led to the significant increase in the activation of caspase-3 (Fig. 3D and E). This result demonstrated that targeting MUCL1 in CRC cells resulted in the inhibition 

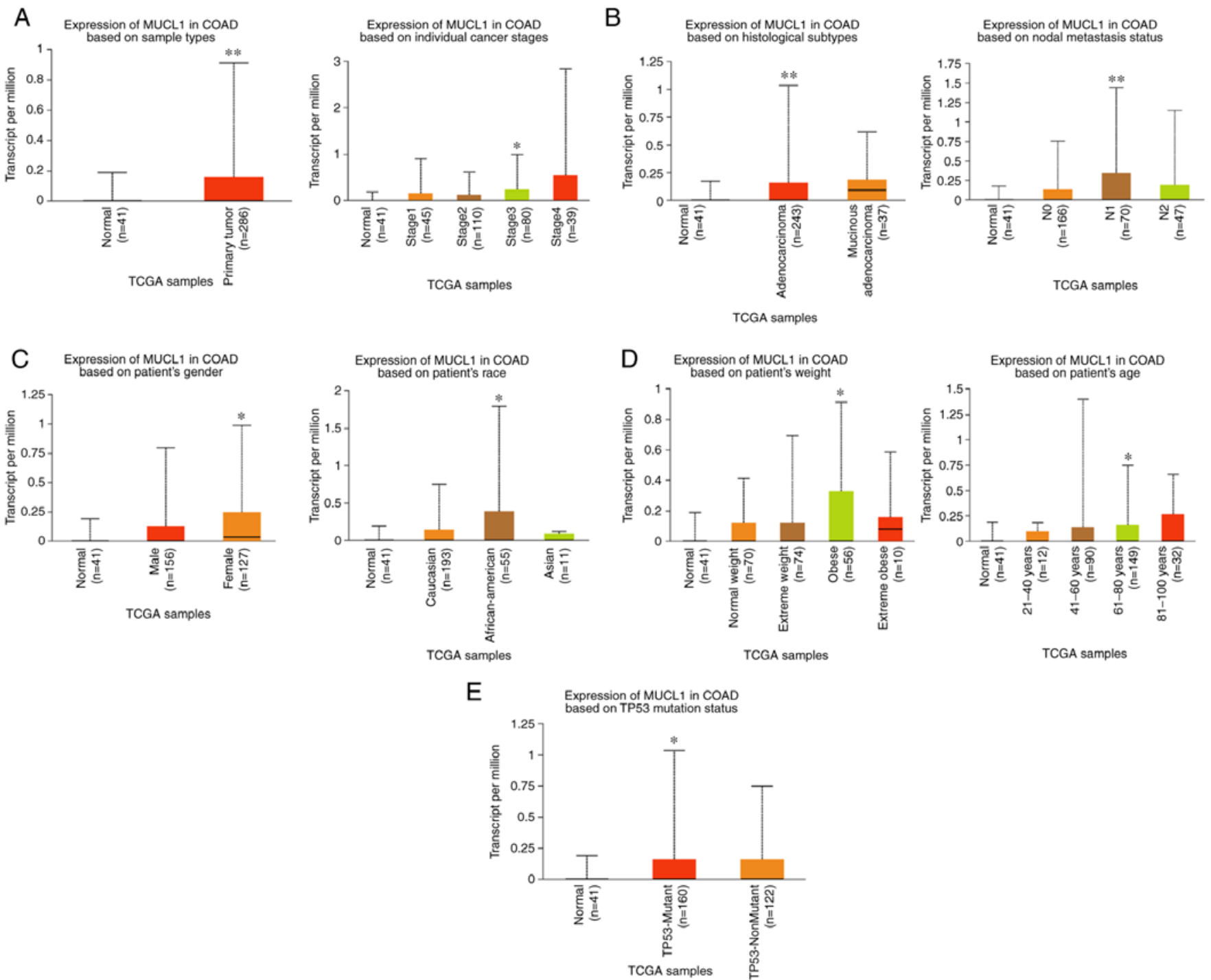

Figure 2. MUCL1 transcription expression in various clinicopathological parameters of COAD. (A) Primary tumors and cancer stages. (B) Histological subtype and nodal metastasis. (C) Sex and race based. (D) Weight and age group based and (E) Based on TP-53 mutation status. ${ }^{*} \mathrm{P}<0.05$, ${ }^{* *} \mathrm{P}<0.01$ vs. normal. MUCL1, mucin-like 1; COAD, colon adenocarcinoma; TCGA, The Cancer Genome Atlas.

of Bcl2 and BclxL and further activation of caspase-3, thereby confirming the significant role of MUCL1 in controlling the apoptotic pathway.

MUCL1 promotes cell proliferation and colony formation. To study the oncogenic potential of MUCL1 in CRC, colony formation assay was performed in HT-29 control siRNA and two MUCL1 siRNA clones. Inhibition of MUCL1 resulted in a significant depletion in the number of colonies in both silenced clones compared with the control (Fig. 4A). Similarly, the colony number was significantly decreased in MUCL1-silenced SW620 cells compared with control siRNA cells (Fig. 4B). To understand the physiological role of MUCL1 in CRC, the cell proliferation was evaluated at different time points. MUCL1-knockdown resulted in the significant inhibition of cell proliferation in HT-29 cells compared with control cells (Fig. 4C). A similar result was observed in the metastatic cell line SW620 (Fig. 4D). These findings thus indicated that MUCL1 expression is notable in mediating the tumorigenesis in CRC.
MUCL1 induces migration and invasion. Cancer metastasis is initiated by invasive behavior of cancer cells and migration process (24). To study the role of MUCL1 in cell invasion and migration, a Transwell assay was performed. The results showed that HT-29 control cells migrated to the lower side of the chambers after $48 \mathrm{~h}$; however silencing MUCL1 significantly inhibited the cell migration compared with control cells (Fig. 5A). Similarly, silencing MUCL1 in SW620 cells also inhibited cell migration significantly compared with control cells (Fig. 5B). The quantification of migrating cells by crystal violet staining demonstrated that MUCL1 silencing significantly inhibited the relative migration ability of HT-29 and SW620 cells by $>70$ and $>80 \%$, respectively (Fig. 5A and B). Furthermore, cell invasion was evaluated using Matrigel-coated inserts. As revealed in Fig. 5C, silencing MUCL1 significantly inhibited the invasive potential of HT-29 compared with control cells. SW620 cells with MUCL1 silencing also demonstrated significant inhibition of cell invasion compared with control cells (Fig. 5D). Invading cells were quantified by crystal violet staining and it was revealed 
A
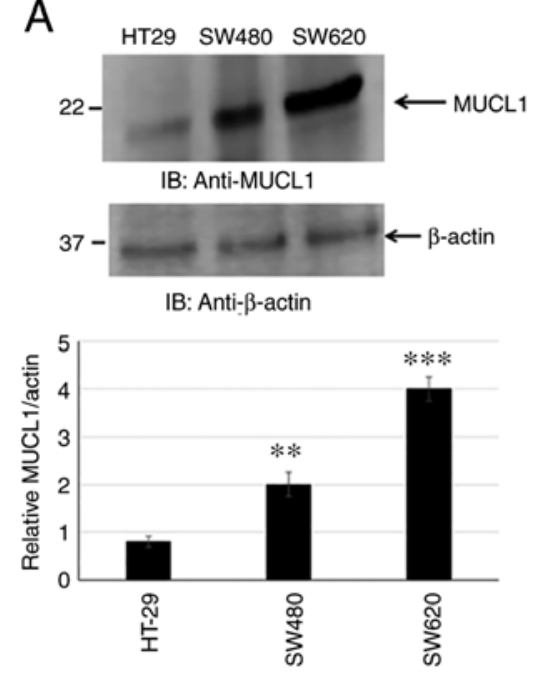

B
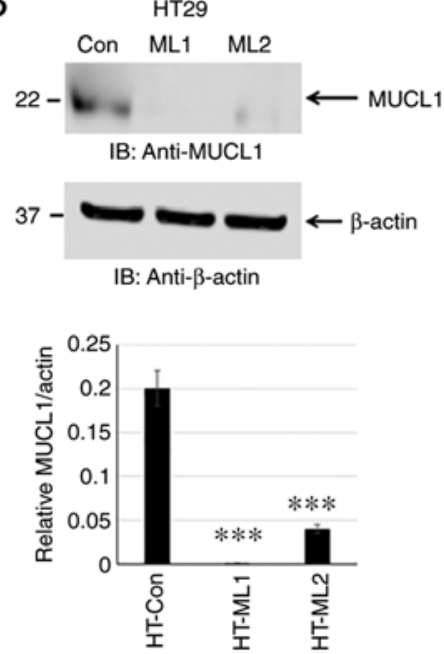

C
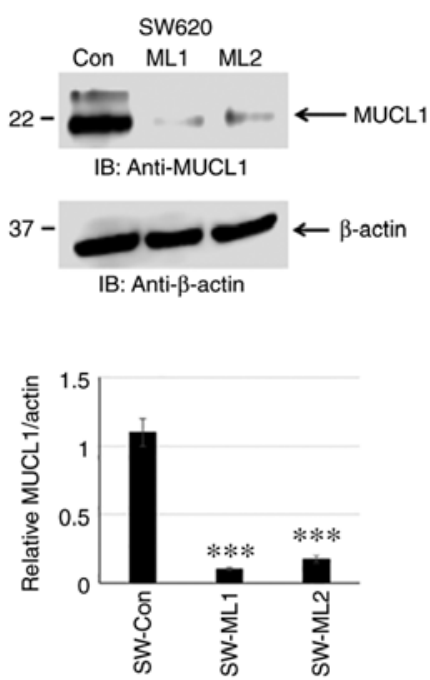
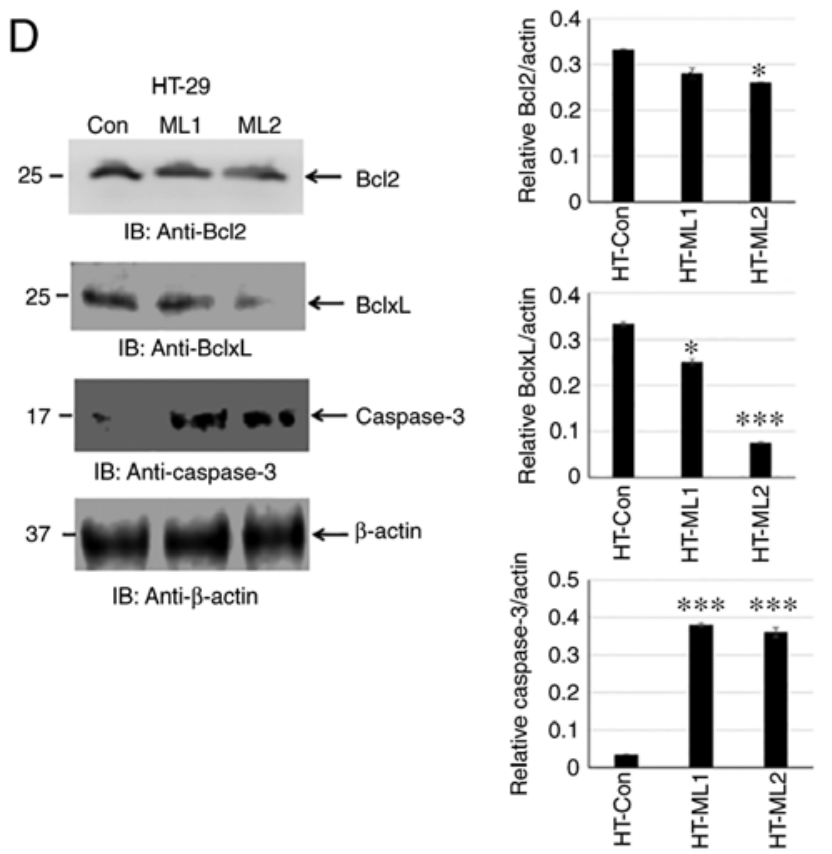

E

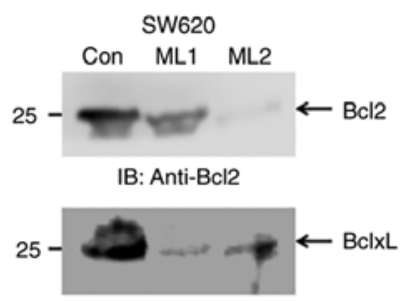

IB: Anti-BcIxL

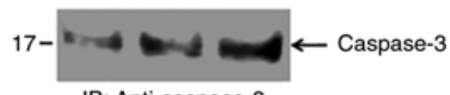

IB: Anti-caspase-3

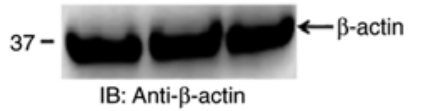

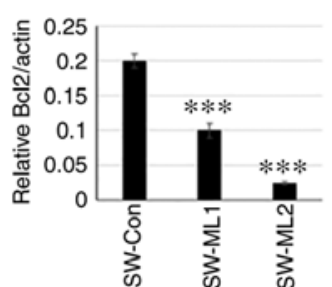

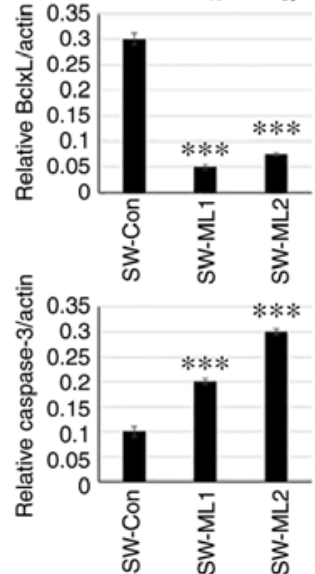

Figure 3. MUCL1 protein expression in human CRC cell lines. (A) Soluble protein of whole cell lysate from HT-29, SW480 and SW620 cells was immunoblotted against the indicated antibodies. (B) Total cell lysate from HT-29-Control siRNA and HT-29-MUCL1siRNA clones ML1 and 2 was immunoblotted against the indicated antibodies. (C) Total cell lysate from SW620 Control siRNA and SW620-MUCL1siRNA clones ML1 and 2 was immunoblotted against the indicated antibodies. (D) Total cell lysate from HT-29-Control siRNA and HT-29-MUCL1 siRNA clones ML1 and 2 was evaluated for the expression of Bcl2, BclxL and caspase-3. (E) Total cell lysate from SW620-Control siRNA and SW620-MUCL1siRNA clones ML1 and 2 was immunoblotted against the indicated antibodies (Bcl2, BclxL and caspase-3). Densitometric analysis was conducted as follows: Intensity of protein bands were semi-quantified and plotted as relative protein expression to control. The bar graphs are presented as the mean $\pm \mathrm{SD}$ of three independent experiments. ${ }^{*} \mathrm{P}<0.05$, ${ }^{* *} \mathrm{P}<0.01$ and ${ }^{* * * *} \mathrm{P}<0.001$ vs. control. MUCL1, mucin-like 1; CRC, colorectal cancer; si-, small interfering; Con, control.

that knockdown of MUCL1 significantly inhibited the relative invasive ability of HT-29 and SW620 cells by $\sim 80$ and $75 \%$, respectively (Fig. $5 \mathrm{C}$ and $\mathrm{D}$ ). These results demonstrated that MUCL1 promotes cell migration and invasion in CRC cells.

MUCL1 promotes EMT by inducing $\beta$-catenin activation. EMT is associated with an invasive and metastatic phenotype in CRC. EMT leads to downregulation of E-cadherin and upregulation of $\mathrm{N}$-cadherin and vimentin by modulating EMT-related signaling pathways, for instance Wnt/ $\beta$-catenin, TGF- $\beta$ and ZEB1 (6-8). The present study investigated if silencing MUCL1 in CRC leads to alteration in E-cadherin and vimentin expression levels. Indeed, silencing MUCL1 in HT-29 cells led to a significant upregulation of E-cadherin and downregulation of vimentin (Fig. 6A). A similar result was observed in SW620 MUCL1 siRNA cells (Fig. 6B). These findings thus indicated that MUCL1 is of importance for EMT process and thereby targeting MUCL1 may lead to potential therapeutics.

The activation of $\beta$-catenin results in EMT and is directly associated with invasion and metastasis of various cancers (8). The activation of $\beta$-catenin in HT-29 control siRNA and MUCL1 siRNA cells was analyzed by measuring $\beta$-catenin-Ser552 phosphorylation. Silencing MUCL1 in HT-29 cells resulted 
A

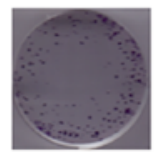

HT-29-Control
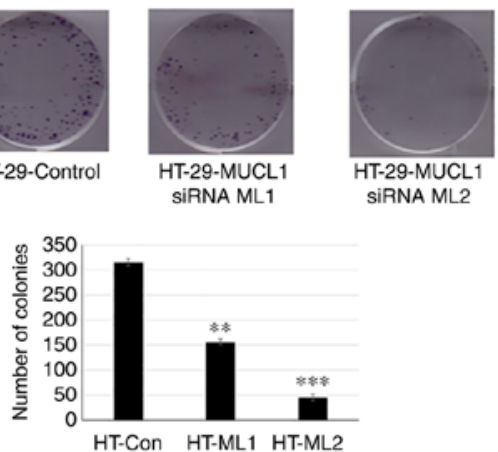

C

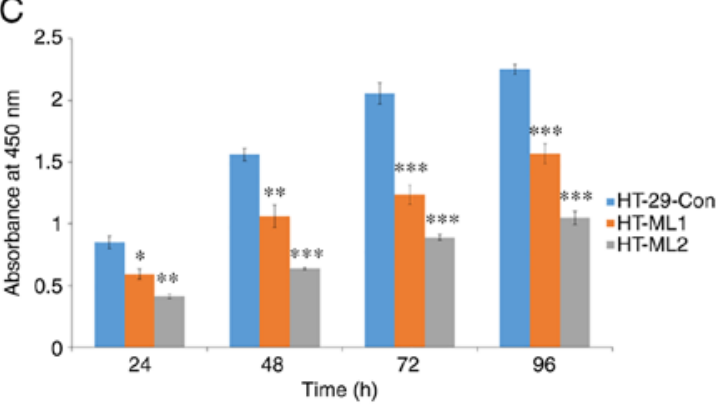

B
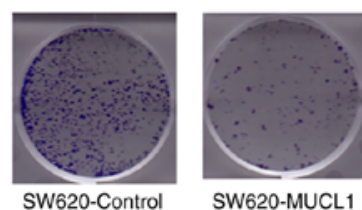

SW620-MUCL1 SIRNA ML1
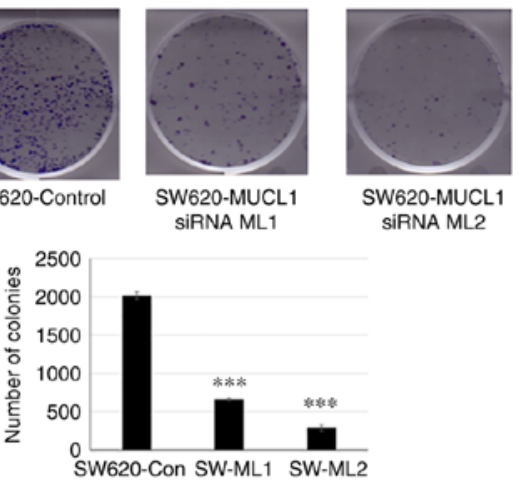

D

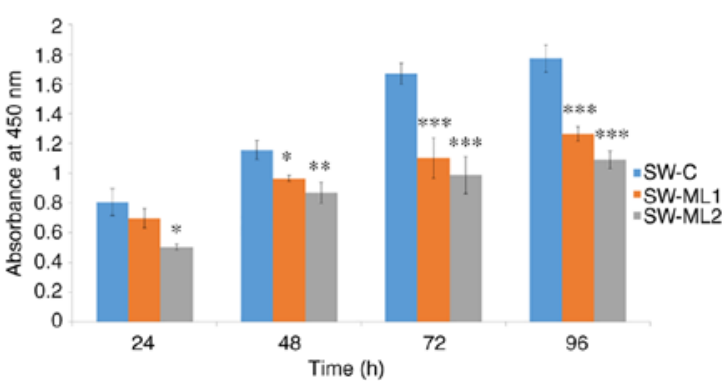

Figure 4. MUCL1 promotes cell proliferation. (A) HT-29-Control siRNA and HT-29-MUCL1 siRNA clones ML1 and 2 and (B) SW620-Control siRNA and SW620-MUCL1 siRNA clones ML1 and 2 cells were seeded (500/well) in 6-well plate and incubated at 37 C. After 10-12 days of incubation crystal violet staining was performed, colonies were quantified and images were captured by Bio-Rad gel-doc system. (C) HT-29-Control siRNA and HT-29-MUCL1 siRNA clones ML1 and 2 were seeded at 5,000 cells/well in 96-well plates and incubated at $37^{\circ} \mathrm{C}$. Cell proliferation was determined by Cell Counting Kit- 8 assay on 24, 48, 72 and $96 \mathrm{~h}$. (D) SW620-Control siRNA and SW620-MUCL1siRNA clone ML1 and 2 cells were seeded at 5,000 cells/well in 96-well plate for incubation at $37^{\circ} \mathrm{C}$. Cell proliferation was measured by CCK-8 assay on 24, 48, 72 and $96 \mathrm{~h}$. The results are expressed as the mean \pm SD of three independent experiments. ${ }^{*} \mathrm{P}<0.05,{ }^{* *} \mathrm{P}<0.01$ and ${ }^{* * * *} \mathrm{P}<0.001$ vs. control. MUCL1, mucin-like 1; si-, small interfering; Con, control.

A
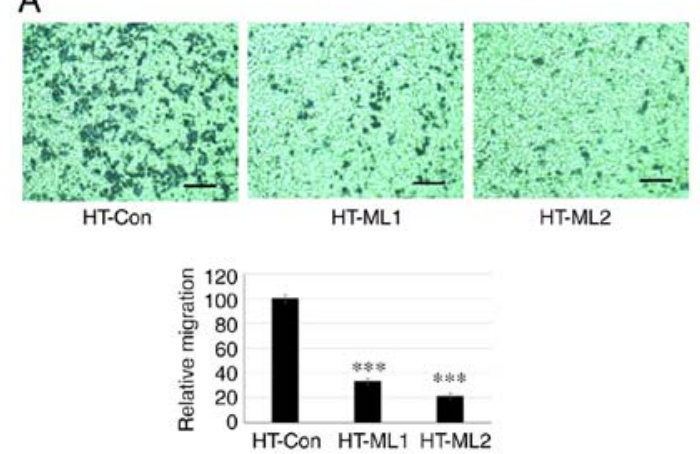

C
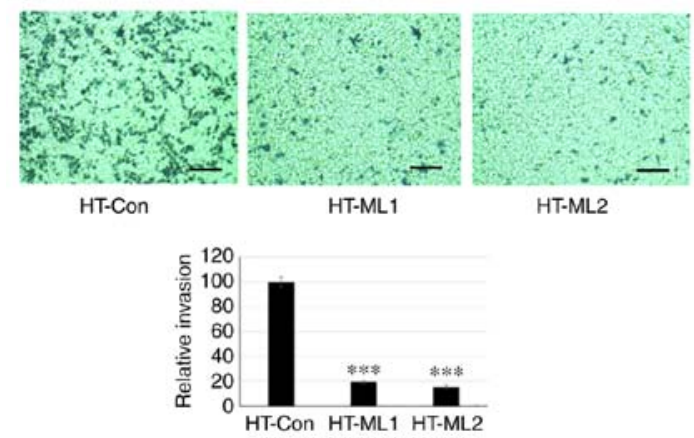

B
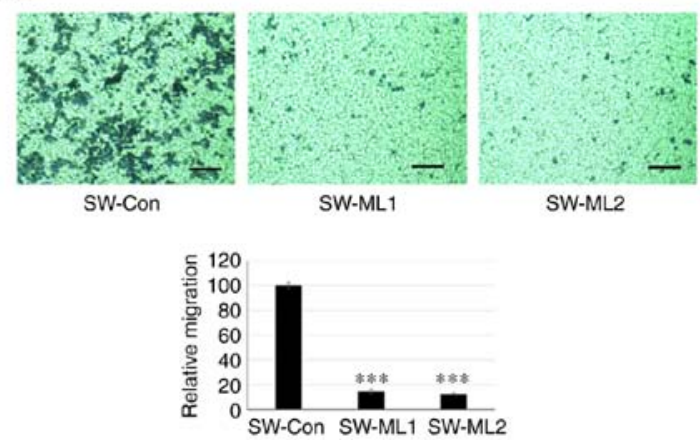

D
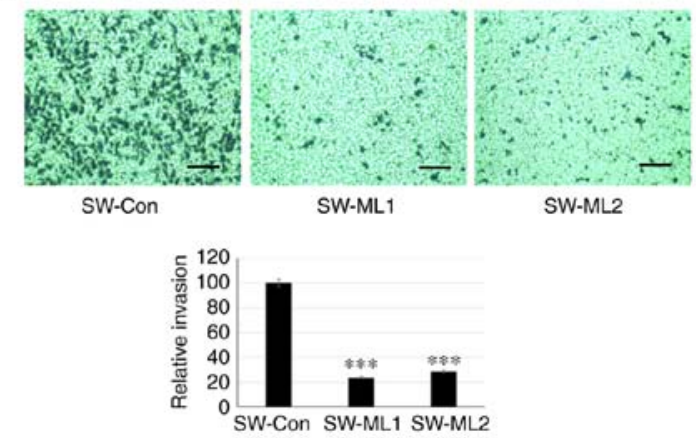

Figure 5. Targeting MUCL1 inhibits migration and invasion. Transwell migration and invasion assay was performed using 24-well plates. Migration and invasion activity were evaluated after $48 \mathrm{~h}$ by crystal violet staining. Quantification of migration was measured as relative migration and compared with control. (A) Migration ability of HT-29-Con siRNA and HT-29-MUCL1siRNA clones ML1 and 2. (B) Migration ability of SW620-Con siRNA and SW620-MUCL1siRNA clones ML1 and 2 plated in Transwell plate inserts. (C) Invasion ability of HT-29-Con siRNA and HT-29-MUCL1siRNA clones ML1 and 2. (D) Invasion ability of SW620-Con siRNA and SW620-MUCL1siRNA clones ML1 and 2 plated in Transwell plate inserts. Invasive activity was determined as relative invasion. All assays were carried out in triplicate. Scale bar, $100 \mu \mathrm{m}$. The results were expressed as the mean \pm SD of three independent experiments. ${ }^{* * * *} \mathrm{P}<0.001$ vs. control. MUCL1, mucin-like 1; si-, small interfering; Con, control. 
A

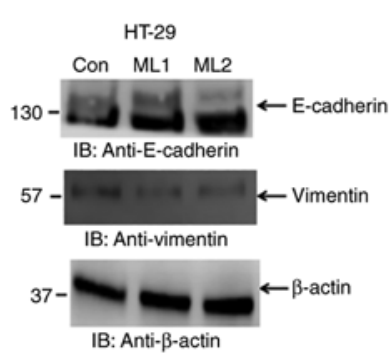

C

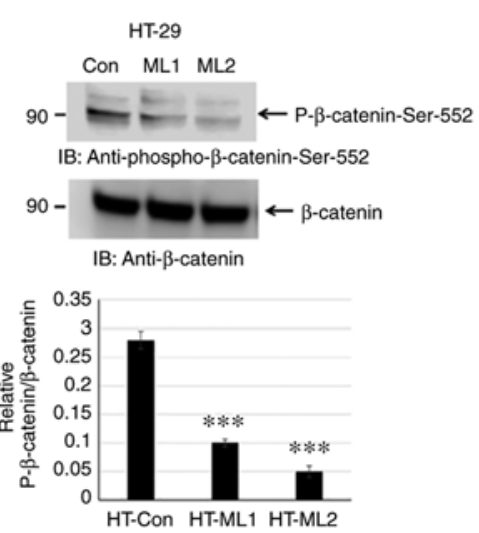

E
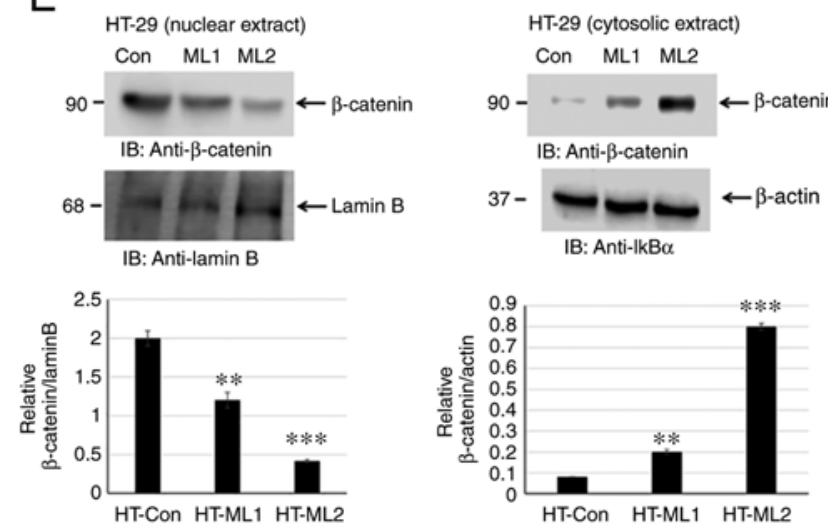
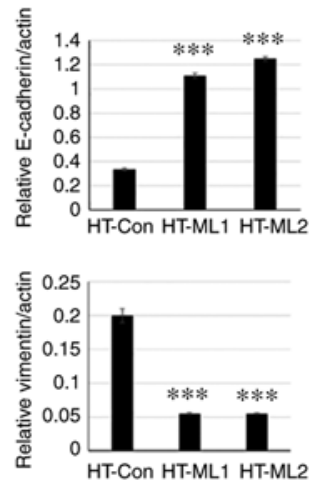

B

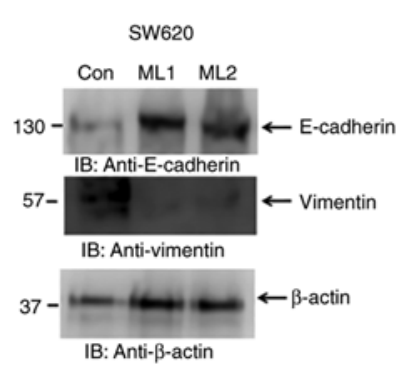

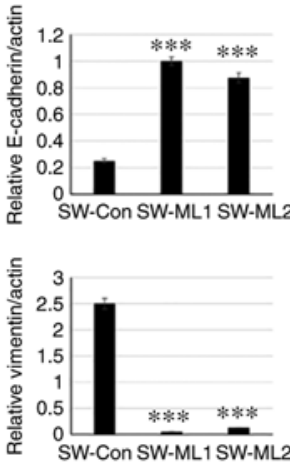

D

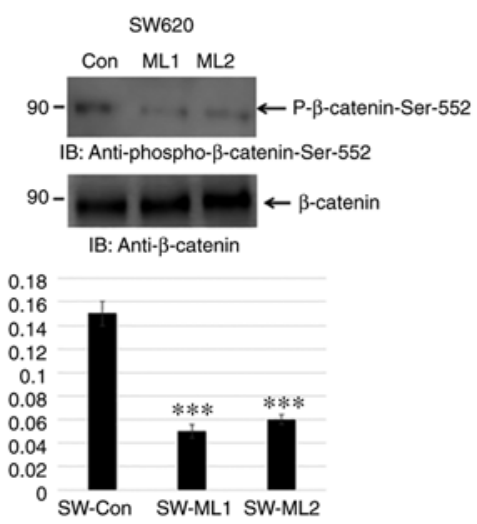

$\mathrm{F}$
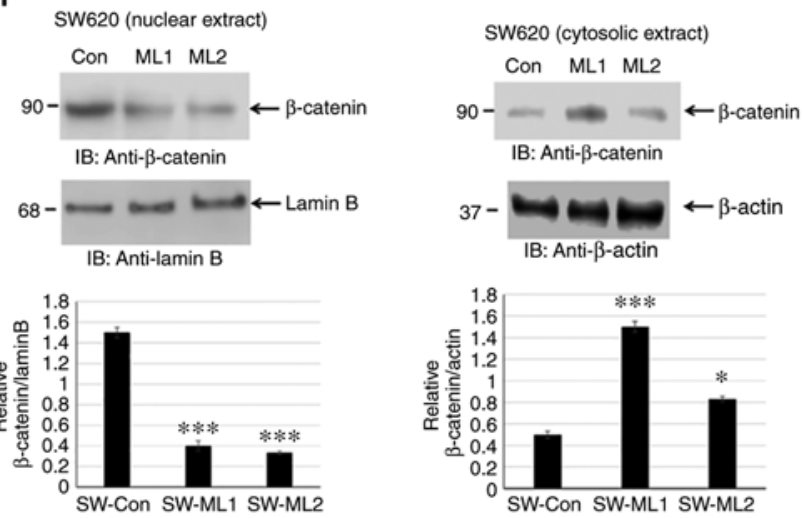

Figure 6. MUCL1 induces epithelial-mesenchymal transition by activating $\beta$-catenin. Total cell lysates from (A) HT-29-Control siRNA and HT-29-MUCL1 siRNA clones ML1 and 2 or (B) from SW620-Control siRNA and SW620-MUCL1 siRNA clones ML1 and 2 cells were immunoblotted against the indicated antibodies (E-cadherin and vimentin). Total cell lysates from (C) HT-29-Control siRNA and HT-29-MUCL1 siRNA clones ML1 and 2 or (D) from SW620-Control siRNA and SW620-MUCL1 siRNA clones ML1 and 2 cells were immunoblotted against the indicated antibodies (phosphor- $\beta$-catenin-Ser-552 and $\beta$-catenin). Nuclear and cytosolic extracts from (E) HT-29-Control siRNA and HT-29-MUCL1 siRNA clones ML1 and 2 or (F) from SW620-Control siRNA and SW620-MUCL1 siRNA clones ML1 and 2 were immunoblotted against the indicated antibodies ( $\beta$-catenin, $\beta$-actin and Lamin B). Densitometric analysis was conducted as follows: Intensity of the protein bands was semi-quantified and plotted as relative protein expression to control. The bar graphs are presented as the mean $\pm \mathrm{SD}$ of three independent experiments. ${ }^{*} \mathrm{P}<0.05,{ }^{* *} \mathrm{P}<0.01$ and ${ }^{* * *} \mathrm{P}<0.001$ vs. control. MUCL1, mucin-like 1; si-, small interfering; Con, control.

in the significant downregulation of $\beta$-catenin-Ser552 phosphorylation compared with control cells (Fig. 6C). Similarly, silencing MUCL1 in SW620 cells resulted in the depletion of phosphorylation of $\beta$-catenin-Ser552 (Fig. 6D).

Translocation of $\beta$-catenin from the cytosol into the nucleus is important for transcriptional activation (25). The present study sought to explore the localization of $\beta$-catenin in nuclear and cytosolic fraction. It was revealed that $\beta$-catenin was maintained in the cytosol during normal homeostasis; however during transformation and tumor progression, $\beta$-catenin translocated into the nucleus to activate $\beta$-catenin responsive genes. $\beta$-catenin was found to be mainly localized in the nucleus in
HT-29 control cells; however inhibiting MUCL1 resulted in the significant depletion of nuclear $\beta$-catenin and significantly increased its cytosolic level (Fig. 6E). Similarly, in SW620 control cells, $\beta$-catenin was mainly localized in nucleus and less in the cytosol (Fig. 6F). MUCL1 knockdown resulted in the inhibition of nuclear levels and enhanced $\beta$-catenin levels in the cytoplasm. Thus, these findings demonstrated that MUCL1 regulates the $\beta$-catenin activation and thereby EMT in CRC cells.

Silencing MUCL1 increases IRI sensitivity. IRI is an integral part of CRC chemotherapy, but response rates are not 
A
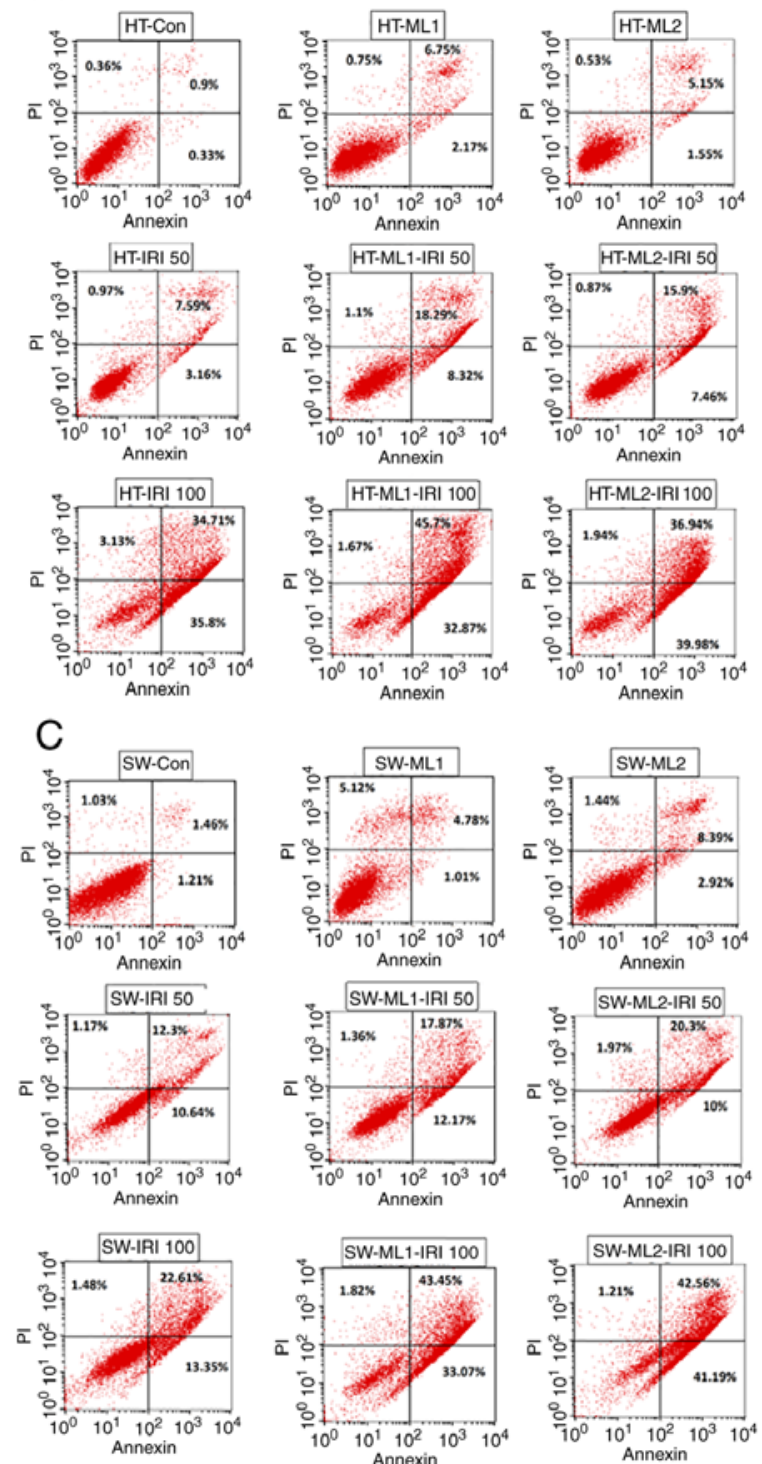
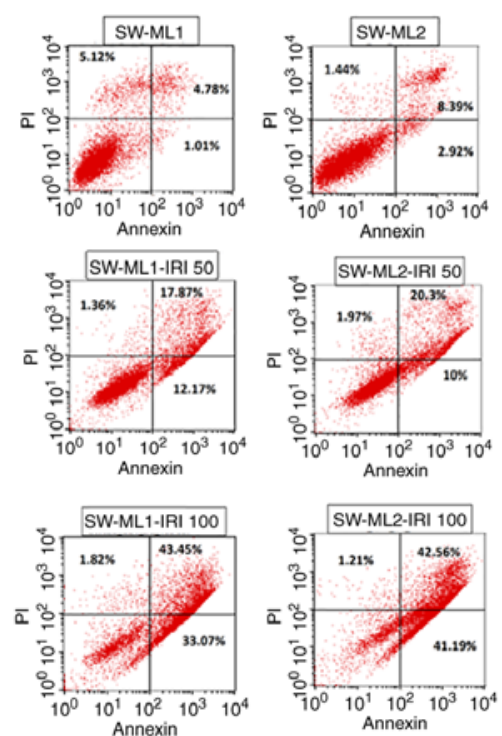

B
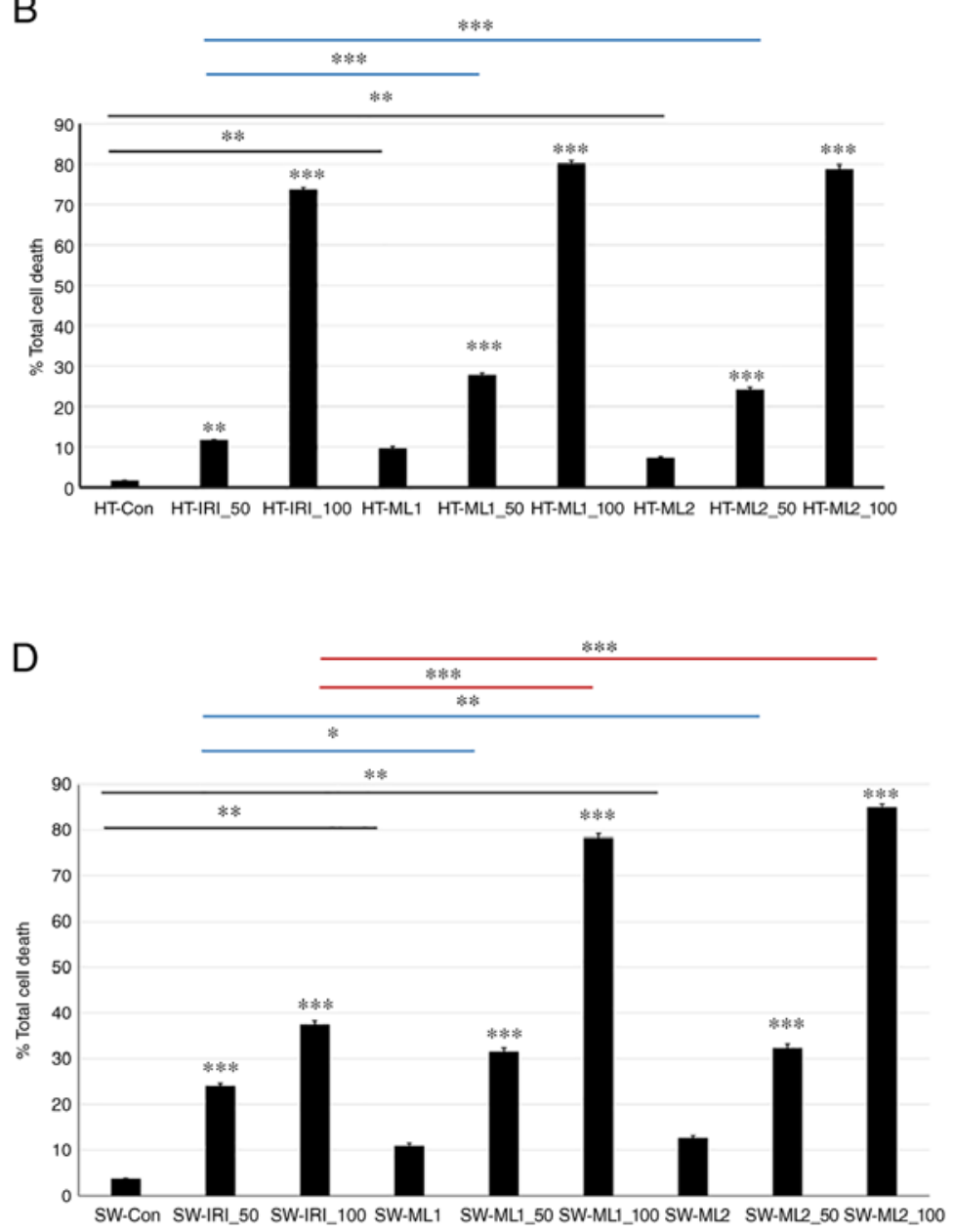

Figure 7. Targeting MUCL1 increases sensitivity towards IRI. (A) HT-29-Control siRNA and HT-29-MUCL1siRNA clones ML1 and 2 cells were treated with IRI (50 and $100 \mu \mathrm{M})$ for $24 \mathrm{~h}$. (B) Percentage of total cell death was analyzed by Annexin V/PI staining using flow cytometry. (C) SW620-Control siRNA and SW620-MUCL1siRNA clones ML1 and 2 cells were exposed to IRI (50 and $100 \mu \mathrm{M}$ ) for $24 \mathrm{~h}$. (D) Total cell death (\%) was analyzed by Annexin V/PI staining using flow cytometry. Total cell death (\%) shown is representative of three independent experiments (n=3). ${ }^{*} \mathrm{P}<0.05,{ }^{* *} \mathrm{P}<0.01$ and ${ }^{* * * *} \mathrm{P}<0.001$ vs. control. HT-ML1/HT-ML2 vs. control (black); HT-ML1-IRI-50/HT-ML2-IRI-50 vs. HT-IRI-50 (blue). SW-ML1/SW-ML2 vs. control (black); SW-ML1-IRI-50/SW-ML2-IRI-50 vs. SW-IRI-50 (blue); SW-ML1-IRI-100/SW-ML2-IRI-100 vs. SW-IRI-100 (red). MUCL1, mucin-like 1; si-, small interfering; Con, control.

satisfactory and resistance mechanisms remain unknown. To understand if MUCL1 regulates drug sensitivity for CRC, HT-29 control and MUCL1 siRNA clones ML1 and 2 were treated with IRI (50 and $100 \mu \mathrm{M}$ ) for $24 \mathrm{~h}$ and analyzed for total cell death by flow cytometry. As revealed in Fig. 7A and B, HT-29 control cells treated with 50 and $100 \mu \mathrm{M}$ of IRI resulted in 11.72 and $73.6 \%$ total cell death respectively compared with untreated cells. Similarly, treatment of HT-ML1 with 50 and $100 \mu \mathrm{M}$ IRI resulted in the significant increase in total cell death of 27.71 and $80.24 \%$ respectively compared with untreated HT-ML1 cells (9.67\%; Fig. 7B). Similar increase was observed with HT-ML2 cells. Treatment of HT-ML2 cells with 50 and $100 \mu \mathrm{M}$ of IRI resulted in the significant induction of total cell death by 24.23 and $78.86 \%$ compared with untreated HT-ML2 cells (Fig. 7B). Untreated HT-ML1 and HT-ML2 cells exhibited significant increase in 9.67 and
$7.23 \%$ total cell death compared with HT-29 control cells (1.6\%). HT-ML1 and HT-ML2 cells treated with $50 \mu \mathrm{M}$ of IRI resulted in 27.71 and $24.23 \%$ total cell death which was significantly higher compared with HT-29-Control siRNA treated cells (50 IRI) (11.71\%). Similarly, treatment of HT-ML1 and HT-ML2 cells with $100 \mu \mathrm{M}$ IRI also showed mild increase in total cell death of 80.24 and $78.86 \%$ compared with control cells (HT-IRI_100; 73.6\%). SW620 control cells treated with 50 and $100 \mu \mathrm{M}$ of IRI were found to significantly increase in total cell death of 24.11 and $37.44 \%$ compared with untreated cells (Fig. 7C). Treatment of SW620-ML1 cells with IRI (50 and $100 \mu \mathrm{M}$ ) exhibited significant increase of 31.4 and $78.34 \%$ total cell death compared with untreated SW-ML1 control cells $(10.91 \%)$. SW-ML2 cells treated with 50 and $100 \mu \mathrm{M}$ of IRI were found to exhibit significant increase of 32.27 and $84.97 \%$ in total cell death compared with $12.75 \%$ 
for untreated SW-ML2 control cells (Fig. 7D). SW-ML1 and SW-ML2 cells treated with $50 \mu \mathrm{M}$ IRI resulted in significant increase of 31.4 and $32.27 \%$ in total cell death compared with SW620 control siRNA cells (treated with 50 IRI) (24.11\%). Treatment of SW-ML1 and SW-ML2 cells with $100 \mu \mathrm{M}$ of IRI resulted in significant increase in total cell death of 78.34 and $84.97 \%$, respectively, compared with SW620 control siRNA cells treated with $100 \mu \mathrm{M}$ IRI (37.44\%). Thus, these findings demonstrated that silencing MUCL1 in HT-29 and SW620 cells resulted in increased sensitivity towards IRI.

\section{Discussion}

Globally, CRC is the third most common detected cancer and second leading cause of cancer-related mortality according to GLOBOCAN 2020 (26). According to the latest JAMA report, a total of $25 \%$ of patients present with advanced localized disease that eventually develops into metastasis and $20 \%$ of patients with CRC have metastasis at diagnosis (27). Treatment for unresectable metastatic CRC involves cytotoxic drugs (5FU, Oxoplatinum and IRI), antibodies (cetuximab and panitumumab) and immunotherapy in combination (27). MUCL1 is a small glycoprotein and belongs to the mucin family of proteins. MUCL1 has been extensively studied in breast cancer mostly as a diagnostic biomarker for micrometastasis (10-13). The therapeutic role of MUCL1 targeting in breast cancer has been previously reported (17). Conley et al (28) reported that Her2 drives MUCL1 expression and regulates cell proliferation in breast cancer. MUCL1 mRNA showed high expression in stomach cancer (29). Aziz et al (30) reported that MUCL1 was upregulated (1.17-fold) in matched-pair CRC tumor. Apart from breast cancer, MUCL1 function has not been explored for any other cancer, to the best of our knowledge.

In the present study, it was demonstrated that MUCL1 gene expression was upregulated in CRC-matched adjacent normal tissues. This finding was confirmed by analyzing the MUCL1 gene expression in CRC using GEPIA and UALCAN database and it was found that its expression was significantly higher compared with normal adjacent tissues. MUCL1 expression has not been reported in human cancer cell lines with the exception of breast cancer. In the present study, for the first time, it was revealed that MUCL1 is highly expressed in human CRC cell lines. HT-29 cells expressed a low amount of MUCL1 protein. MUCL1 exhibited moderate to high expression in SW480 and higher expression in SW620 cells. MUCL1 expression varied from low in adenocarcinoma to high in metastatic CRC cells.

To understand the potential oncogenic role of MUCL1 in CRC, MUCL1 was silenced in HT-29 and SW620 cells and functional studies were performed. In the present study, MUCL1-silencing inhibited cell proliferation and colony formation of CRC cell lines. Knockdown of MUCL1 in CRC cell lines resulted in the downregulation of antiapoptotic proteins $\mathrm{Bcl} 2$ and $\mathrm{BclxL}$, confirming its role in the regulation of cancer cell survival. Furthermore, targeting MUCL1 showed activation of caspase-3, which indicated that it plays an important role in apoptosis.

Dysregulation of the $\mathrm{Bcl} 2$ family proteins are of prime significance for targeting CRC (31). Bcl2 and BclxL proteins are important regulators of proliferation and apoptosis and have been implicated in CRC initiation, progression and metastasis (31). Targeting MUCL1 protein provides a therapeutic opportunity to inhibit the $\mathrm{Bcl} 2$-related pathway and evaluate their potential for CRC treatment. Conley et al (28) identified that MUCL1 knockdown led to cell cycle arrest by altering the cell cycle inducers (Cyclin D1 and D3) and inhibitors (p21 and p27) and proposed that MUCL1 interacts with focal adhesion kinase (FAK); thereby leading to its activation and further activation of the JNK-cJun pathway, resulting in modulation of the cell cycle. Cell invasion and motility play a key role in cancer cell migration to distant metastasis (6). MUCL1 silencing inhibited the migration ability of CRC cells. MUCL1-silenced HT-29 and SW620 cells showed inhibition in the number of invasive cells compared with control siRNA cells, which exhibited significantly higher invasion ability. Li et al (17) showed that knockdown of MUCL1 in MCF7 and MDA-MB-231 inhibited the invasion and migration.

EMT is a biological process by which epithelial cells acquire mesenchymal characteristics (32). EMT plays an important role in embryonic development, tissue fibrosis and tumor progression (33). During tumor progression, mesenchymal phenotype with malignant feature associates with migration, invasion and metastasis (34). The loss of E-cadherin and upregulation of $\mathrm{N}$-cadherin/vimentin is considered as a key feature of EMT (7). Therefore, blocking the EMT process serves as an attractive target for cancer therapeutics. In the present study, it was found that MUCL1 silencing inhibited EMT phenomenon, as evidenced by increased E-cadherin and decreased vimentin expression levels. Consistent with the aforementioned finding, it was previously reported that knockdown of MUCL1 in breast cancer cells inhibits EMT (17). The mucin proteins, specifically MUC1, have been shown to play a key role in tumorigenesis by integrating EMT program (35). The C-terminus of MUC1 induces EMT by activating $\mathrm{NF} \kappa \mathrm{B}$ pathway and ZEB1, a well-known transcription suppressor of EMT in breast and colon cancer (35-38). The Wnt pathway effector, $\beta$-catenin, plays important roles in proliferation, survival and EMT of CRC cells. Knockdown of MUCL1 in CRC cell lines resulted in the inhibition of $\beta$-catenin activation, as shown by decreased phosphorylation of Ser-552. Phosphorylation of $\beta$-catenin-Ser 552 by AKT/PKA induces nuclear accumulation and transcription activation $(39,40)$. Cellular fractionation of control and MUCL1 siRNA cells indicated that targeting MUCL1 resulted in inhibition of nuclear $\beta$-catenin and increased its appearance in the cytosol. This finding confirmed that MUCL1 regulates $\beta$-catenin and thereby EMT.

A previous study has supported the critical role of $\beta$-catenin in regulating EMT (41). The role of mucin in regulating $\beta$-catenin has been extensively studied $(9,42)$. MUCL1 regulates the $\beta$-catenin in CRC. The results of the present study showed that silencing MUCL1 inhibited phosphorylation of $\beta$-catenin-Ser556 and depleted the nuclear accumulation. In the absence of Wnt, GSK-3 $\beta$ and CK1 phosphorylate $\beta$-catenin (Ser-33, -37, Thr-41) in the cytosol, leading to interaction with the destruction complex (APC, GSK3 $\beta$, CK1, Axin) (25). This destruction complex binds to the E3 ubiquitin ligase $(\beta$-TrCP) through the $\beta$-catenin, which enhances its ubiquitination leading to proteasomal degradation (25). In cancer cells with Wnt activation, the Wnt-Frizzled-Axin-LRP-5/6 
complex sequesters cytosolic GSK-3 $\beta$, thereby blocking the phosphorylation of $\beta$-catenin (25). This leads to accumulation of non-phosphorylated $\beta$-catenin in the cytosol, which translocates to the nucleus, binds to $\mathrm{T}$ cell-specific factor/lymphoid enhancer-binding factor and co-activators on the promoter to activate the target genes (c-Myc, cyclin D1 and Cdkn1a) (25). Other oncogenes and modifiers also block upstream kinases (CK and GSK3 $\beta$ ) leading to nuclear translocation of $\beta$-catenin (25). In the present study, MUCL1 expression increased the translocation of $\beta$-catenin from cytosol into nucleus, and thereby increased transcriptional activation of its target genes.

MUC1-C has been shown to bind directly to $\beta$-catenin and regulate its transcription (43). MUC1, MUC4 and MUC16 have been shown to regulate localization and transcriptional activation of $\beta$-catenin $(42,43)$. Similar to these mucins, the present study demonstrated that MUCL1 influenced the nuclear localization and stabilization of $\beta$-catenin. With known correlation between MUC1 and the $\beta$-catenin pathway (43), MUCL1 may regulate $\beta$-catenin directly or indirectly through upstream kinases. FAK could be one such kinase that may activate $\beta$-catenin by interacting with MUCL1. There is increasing evidence of a functional crosstalk between the FAK and Wnt $\beta$-catenin signaling pathways during cancer progression $(44,45)$. This may serve an interesting area for future study to elucidate the direct link between MUCL1- $\beta$-catenin.

Finally, the physiological significance of MUCL1 in increasing sensitivity towards anticancer drug for CRC was investigated. Tumor resistance is a frequent cause of chemotherapy failure. New treatments are required to improve survival of CRC patients specifically in IRI refractory patients. IRI (IRI/CPT-11) in combination with 5-FU and the modulator leucovorin, has been approved as first-line chemotherapy for patients with mCRC $(46,47)$. Knockdown of MUCL1 in CRC cell lines increased the total cell death in response to IRI compared with control siRNA cells. Interestingly, it was demonstrated that IRI $(50 \mu \mathrm{M})$ showed higher sensitivity in HT-29 cells compared with $100 \mu \mathrm{M}$ of IRI. In SW620 cells, both 50 and $100 \mu \mathrm{M}$ of IRI displayed increased sensitivity in MUCL1-silenced cells compared with the control. This dose difference in response could be due to different mutation status in these cell lines and cell origin. IRI resistance in CRC is attributed to Topo I expression level, Topo I mutation, $\mathrm{NF \kappa B}$ activation and ABC family of drug transporters (48). Cdk1 inhibition enhanced IRI sensitivity in human CRC cells (HT-29) (49). A previous study revealed that low expression of ABCG2 showed increased sensitivity to IRI in colorectal adenocarcinoma (50). FGFR3 overexpression alters IRI-induced apoptosis in CRC (51). In consistency with these reports, the results of the present study supported that MUCL1 is overexpressed in CRC and that targeting MUCL1 enhanced IRI-mediated apoptosis. In conclusion, MUCL1: i) acts as a modifier of other pathways that drive proliferation and colony formation in CRC cell lines; ii) is necessary for expression of the Bcl2 family protein; iii) enhances invasion and migration; and iv) induces EMT and $\beta$-catenin activation. Consistent with these results, targeting MUCL1 enhances IRI sensitivity in CRC. Thus, MUCL1 alters other pathways that are important for CRC progression, and MUCL1 may act as a potential target for CRC therapeutics.

\section{Acknowledgements}

The present study was supported by the Deanship of Scientific Research, King Saud University, through the Vice Deanship of Scientific Research Chairs.

\section{Funding}

No funding was received.

\section{Availability of data and materials}

All data generated or analyzed during this study are included in this published article.

\section{Authors' contributions}

RA and MA conceptualized the idea, designed and performed the experiments and wrote the manuscript. MAVM, MSEW, NA and TBT performed experiments. KAK, AZ and OAO analyzed the data. All authors have read and approved the final version of the manuscript. RA and MA confirm the authenticity of all the raw data.

\section{Ethics approval and consent to participate}

Not applicable.

\section{Patient consent for publication}

Not applicable.

\section{Competing interests}

The authors declare that they have no competing interests.

\section{References}

1. Ahmad R, Singh JK, Wunnava A, Al-Obeed O, Abdulla M and Srivastava SK: Emerging trends in colorectal cancer: Dysregulated signaling pathways (Review). Int J Mol Med 47: 14, 2021.

2. Alsanea N, Abduljabbar AS, Alhomoud S, Ashari LH, Hibbert D and Bazarbashi S: Colorectal cancer in Saudi Arabia: Incidence, survival, demographics and implications for national policies. Ann Saudi Med 35: 196-202, 2015.

3. Bazarbashi S, Al Eid H and Minguet J: Cancer Incidence in Saudi Arabia: 2012 Data from the Saudi cancer registry. Asian Pac J Cancer Prev 18: 2437-2444, 2017.

4. Riihimäki M, Hemminki A, Sundquist J and Hemminki K: Patterns of metastasis in colon and rectal cancer. Sci Rep 6: 29765, 2016.

5. Andersen $\mathrm{NN}$ and Jess T: Has the risk of colorectal cancer in inflammatory bowel disease decreased? World J Gastroenterol 19: 7561-7568, 2013.

6. Hu Y, Zheng Y, Dai M, Wu J, Yu B, Zhang H, Kong W, Wu H and Yu X: Snail2 induced E-cadherin suppression and metastasis in lung carcinoma facilitated by G9a and HDACs. Cell Adh Migr 13: 285-292, 2019.

7. KaszakI,Witkowska-Piłaszewicz O,NiewiadomskaZ,DworeckaKaszak B, Ngosa Toka F and Jurka P: Role of cadherins in cancer-a review. Int J Mol Sci 21: 7624, 2020.

8. Kim WK, Kwon Y, Jang M, Park M, Kim J, Cho S, Jang DG, Lee WB, Jung SH, Choi HJ, et al: $\beta$-catenin activation down-regulates cell-cell junction-related genes and induces epithelial-to-mesenchymal transition in colorectal cancers. Sci Rep 9: 18440, 2019. 
9. Kufe DW: Mucins in cancer: Function, prognosis and therapy Nat Rev Cancer 9: 874-885, 2009.

10. Colpitts TL, Billing P, Granados E, Hayden M, Hodges S, Roberts L, Russell J, Friedman P and Stroupe S: Identification and immunohistochemical characterization of a mucin-like glycoprotein expressed in early stage breast carcinoma. Tumour Biol 23: 263-278, 2002.

11. Miksicek RJ, Myal Y, Watson PH, Walker C, Murphy LC and Leygue E: Identification of a novel breast- and salivary gland-specific, mucin-like gene strongly expressed in normal and tumor human mammary epithelium. Cancer Res 62: 2736-2740, 2002.

12. Skliris GP, Hubé F, Gheorghiu I, Mutawe MM, Penner C, Watson PH, Murphy LC, Leygue E and Myal Y: Expression of small breast epithelial mucin (SBEM) protein in tissue microarrays (TMAs) of primary invasive breast cancers. Histopathology 52: 355-369, 2008.

13. Ayerbes MV, Diaz-Prado S, Ayude D, Campelo RG, Iglesias P, Haz M, Medina V, Gallegos I and Quindós M: In silico and in vitro analysis of small breast epithelial mucin as a marker for bone marrow micrometastasis in breast cancer. Adv Exp Med Biol 617: 331-339, 2008

14. Valladares-Ayerbes M, Iglesias-Diaz P, Diaz-Prado S, Ayude D Medina V, Haz M, Reboredo M, Antolín S, Calvo L and Antón-Aparicio LM: Diagnostic accuracy of small breast epithelial mucin mRNA as a marker for bone marrow micrometastasis in breast cancer: A pilot study. J Cancer Res Clin Oncol 135: $1185-1195,2009$.

15. Weigelt B, Verduijn P, Bosma AJ, Rutgers EJ, Peterse HL and van't Veer LJ: Detection of metastases in sentinel lymph nodes of breast cancer patients by multiple mRNA markers. Br J Cancer 90: 1531-1537, 2004.

16. Liu ZZ, Xie XD, Qu SX, Zheng ZD and Wang YK: Small breast epithelial mucin (SBEM) has the potential to be a marker for predicting hematogenous micrometastasis and response to neoadjuvant chemotherapy in breast cancer. Clin Exp Metastasis 27: 251-259, 2010

17. Li QH, Liu ZZ, Ge YN, Liu X, Xie XD, Zheng ZD, Ma YH and Liu B: Small breast epithelial mucin promotes the invasion and metastasis of breast cancer cells via promoting epithelial-to-mesenchymal transition. Oncol Rep 44: 509-518, 2020.

18. Tang Z, Li C, Kang B, Gao G, Li C and Zhang Z: GEPIA: A web server for cancer and normal gene expression profiling and interactive analyses. Nucleic Acids Res 45: W98-W102, 2017.

19. Chandrashekar DS, Bashel B, Balasubramanya SAH, Creighton CJ, Ponce-Rodriguez I, Chakravarthi BVSK and Varambally S: UALCAN: A portal for facilitating tumor subgroup gene expression and survival analyses. Neoplasia 19: 649-658, 2017.

20. Al-Khayal K, Vaali-Mohammed MA, Elwatidy M, Bin Traiki T, Al-Obeed O, Azam M, Khan Z, Abdulla M and Ahmad R: A novel coordination complex of platinum (PT) induces cell death in colorectal cancer by altering redox balance and modulating MAPK pathway. BMC Cancer 20: 685, 2020.

21. Vishnubalaji R, Hamam R, Abdulla MH, Mohammed MA, Kassem M, Al-Obeed O, Aldahmash A and Alajez NM: Genome-wide mRNA and miRNA expression profiling reveal multiple regulatory networks in colorectal cancer. Cell Death Dis 6: e1614, 2015.

22. Hardwick JM and Soane L: Multiple functions of Bcl2 family proteins. Cold Spring Harb Prospect Biol 5: a008722, 2013.

23. Baig S, Seevasant I, Mohamad J, Mukheem A, Huri HZ and Kamarul T: Potential of apoptotic pathway-targeted cancer therapeutic research: Where do we stand? Cell Death Dis 7: e2058, 2016

24. Fares J, Fares MY, Khachfe HH, Salhab HA and Fares Y: Molecular principles of metastasis: A hallmark of cancer revisited. Sig Transduct Target Ther 5: 28, 2020.

25. Valenta T, Hausmann $\mathrm{G}$ and Basler K: The many faces and functions of $\beta$-catenin. EMBO J 31: 2714-2736, 2012

26. Siegel RL, Miller KD, Goding Sauer A, Fedewa SA, Butterly LF, Anderson JC, Cercek A, Smith RA and Jemal A: Colorectal cancer statistics, 2020. CA Cancer J Clin 70: 145-164, 2020.

27. Biller LH and Schrag D: Diagnosis and treatment of metastatic colorectal cancer: A review. JAMA 325: 669-685, 2021.

28. Conley SJ, Bosco EE, Tice DA, Hollingsworth RE, Herbst R and Xiao Z: HER2 drives Mucin-like 1 to control proliferation in breast cancer cells. Oncogene 35: 4225-4234, 2016.

29. King RJ, Yu F and Singh PK: Genomic alterations in mucins across cancers. Oncotarget 8: 67152-67168, 2017.

30. Aziz MA, AlOtaibi M, AlAbdulrahman A, AlDrees M and AlAbdulkarim I: Mucin family genes are downregulated in colorectal cancer patients. J Carcinogene Mutagene S10: 009, 2014.
31. Ramesh P and Medema JP: BCL-2 family deregulation in colorectal cancer: Potential for $\mathrm{BH} 3$ mimetics in therapy. Apoptosis 25: 305-320, 2020.

32. Thiery JP, Acloque H, Huang RY and Nieto MA: Epithelial-mesenchymal transitions in development and disease. Cell 139: 871-890, 2009.

33. Nieto MA, Huang RY, Jackson RA and Thiery JP: EMT: 2016. Cell 166: 21-45, 2016.

34. De Craene B and Berx G: Regulatory networks defining EMT during cancer initiation and progression. Nat Rev Cancer 13: 97-110, 2013

35. Rajabi H, Alam M, Takahashi H, Kharbanda A, Guha M, Ahmad R and Kufe D: MUC1-C oncoprotein activates the ZEB1/miR-200c regulatory loop and epithelial-mesenchymal transition. Oncogene 33: 1680-1689, 2014.

36. Takahashi H, Jin C, Rajabi H, Pitroda S, Alam M, Ahmad R, Raina D, Hasegawa M, Suzuki Y, Tagde A, et al: MUC1-C activates the TAK1 inflammatory pathway in colon cancer. Oncogene 34: 5187-5197, 2015.

37. Ahmad R, Raina D, Trivedi V, Ren J, Rajabi H, Kharbanda S and Kufe D: MUC1 oncoprotein activates the IkappaB kinase beta complex and constitutive NF-kappaB signalling. Nat Cell Biol 9: $1419-1427,2007$

38. Ahmad R, Raina D, Joshi MD, Kawano T, Kharbanda S and Kufe D: MUC1-C oncoprotein functions as a direct activator of the nuclear factor-kappaB p65 transcription factor. Cancer Res 69: 7013-7021, 2009.

39. Liu C, Li Y, Semenov M, Han C, Baeg GH, Tan Y, Zhang Z, Lin $\mathrm{X}$ and $\mathrm{He} \mathrm{X}$ : Control of beta-catenin phosphorylation/degradation by a dual-kinase mechanism. Cell 108: 837-847, 2002.

40. Fang D, Hawke D, Zheng Y, Xia Y, Meisenhelder J, Nika H, Mills GB, Kobayashi R, Hunter T and Lu Z: Phosphorylation of beta-catenin by AKT promotes beta-catenin transcriptional activity. J Biol Chem 282: 11221-11229, 2007.

41. Sánchez-Tilló E, de Barrios O, Siles L, Cuatrecasas M, Castells A and Postigo A: $\beta$-catenin/TCF4 complex induces the epithelial-to-mesenchymal transition (EMT)-activator ZEB1 to regulate tumor invasiveness. Proc Natl Acad Sci USA 108 19204-19209, 2011.

42. Pai P, Rachagani S, Dhawan P and Batra SK: Mucins and Wnt/ $\beta$-catenin signaling in gastrointestinal cancers: An unholy nexus. Carcinogenesis 37: 223-232, 2016.

43. Huang L, Chen D, Liu D, Yin L, Kharbanda S and Kufe D: MUC oncoprotein blocks glycogen synthase kinase 3beta-mediated phosphorylation and degradation of beta-catenin. Cancer Res 65 10413-10422, 2005

44. Wörthmüller J and Rüegg C: The crosstalk between FAK and Wnt signaling pathway in cancer and its therapeutic implication. Int J Mol Sci 21: 9107, 2020.

45. Gao C, Chen G, Kuan SF, Zhang DH, Schlaepfer DD and Hu J: FAK/PYK 2 promotes the Wnt/ $\beta$-catenin pathway and intestinal tumorigenesis by phosphorylating GSK3 $\beta$. Elife 4: e10072, 2015.

46. Rougier P and Mitry E: Review of the role of CPT-11 in the treatment of colorectal cancer. Clin Colorectal Cancer 1: 87-94, 2001.

47. Vanhoefer U, Harstrick A, Achterrath W, Cao S, Seeber S and Rustum YM: Irinotecan in the treatment of colorectal cancer: Clinical overview. J Clin Oncol 19: 1501-1518, 2001.

48. Xu Y and Villalona-Calero MA: Irinotecan: Mechanisms of tumor resistance and novel strategies for modulating its activity. Ann Oncol 13: 1841-1851, 2002.

49. Abal M, Bras-Goncalves R, Judde JG, Fsihi H, De Cremoux P, Louvard D, Magdelenat H, Robine S and Poupon MF: Enhanced sensitivity to irinotecan by Cdk1 inhibition in the p53-deficient HT29 human colon cancer cell line. Oncogene 23: 1737-1744, 2004.

50. Tuy HD, Shiomi H, Mukaisho KI, Naka S, Shimizu T, Sonoda H, Mekata E, Endo Y, Kurumi Y, Sugihara H, et al: ABCG2 expression in colorectal adenocarcinomas may predict resistance to irinotecan. Oncol Lett 12: 2752-2760, 2016.

51. Erdem ZN, Schwarz S, Drev D, Heinzle C, Reti A, Heffeter P, Hudec X, Holzmann K, Grasl-Kraupp B, Berger W, et al: Irinotecan upregulates fibroblast growth factor receptor 3 expression in colorectal cancer cells, which mitigates irinotecan induced apoptosis. Transl Oncol 10: 332-339, 2017.

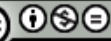

This work is licensed under a Creative Commons Attribution-NonCommercial-NoDerivatives 4.0 International (CC BY-NC-ND 4.0) License. 